\title{
Optimization of Design and Management of a Hydroponic Greenhouse by Using BIM Application Software
}

\author{
Fabrizio Cumo $^{1 *}$, Giuseppe Piras ${ }^{2}$, Elisa Pennacchia ${ }^{1}$, Federico Cinquepalmi $^{3}$ \\ ${ }^{1}$ Department of Planning Design and Technology of Architecture, Sapienza University of Rome, Rome 00196, Italy \\ ${ }^{2}$ Interdepartmental Centre for Territory, Building, Conservation and Environment, Sapienza University of Rome, Rome 00197, \\ Italy \\ ${ }^{3}$ MIUR - Italian Ministry for University and Research, Rome 00153, Italy
}

Corresponding Author Email: fabrizio.cumo@ uniroma1.it

https://doi.org/10.18280/ijsdp.150205

Received: 10 October 2019

Accepted: 26 February 2020

\section{Keywords:}

hydroponic greenhouses, receptive facilities, mobile and modular structures, BIM application software, energy efficiency, climate control

\begin{abstract}
The paper deals with hydroponic greenhouses that can be used both for crops cultivation and as a space for hosting events, thanks to its transformability characteristics. The project combines the concepts of circular economy and agricultural activity, creating environmentally sustainable hydroponic greenhouses, from the design to the management phase, thanks to the use of a multidisciplinary BIM approach (Building Information Modelling). The use of application software in BIM logic such as MC4® Energy and Arch Energy (Tool developed by Sapienza University of Rome) for the energetic performance evaluation and Tally® Environmental Impact Tool for LCA Analysis, has improved the design of a modular and flexible architecture, energy-efficient and water-efficient, with advanced climate control. The project offers a possible solution to the main future challenges of food production such as the limited space, the urbanization process, the scarce availability of resources such as water, fossil fuels, minerals and the increasing demands of consumers in terms of functionality and product quality.
\end{abstract}

\section{INTRODUCTION}

According to FAO's report, in 2050 there will be 2.3 billion more people to feed; so, the agricultural sector, in addition to the substantial increasing of the overall production will have to deal with the problems related to poverty, scarcity of resources and climate change [1].

In fact, agriculture is particularly vulnerable to a large variety of risks such as weather-related dangers (droughts, floods, high winds), pest infestation, plant diseases and market and financial risks; they can negatively affect livelihoods, farmers' incomes, and the capacity of the sector to innovate and invest.

The 2030 Agenda for Sustainable Development recognizes the central role of agriculture in feeding the planet and SDG2 identifies the goals for future agricultural policies to end hunger, guarantee food security, optimize nutrition and support sustainable agriculture [2].

Alongside the need to produce healthy food, there is the need to find solutions to reduce the environmental impact of cultivation. Traditional agriculture, especially intensive agriculture, causes soil consumption and often damages soil and environment due to the use of chemical fertilizers and pesticides. The hydroponic cultivation is relevant for circular economy and for sustainable development because has production capacity up to 10 times higher than open fieldbased agriculture per ha, and its high potential for the recycling of water and nutrients, and high productivity with reduced water and agrochemicals use per unit of production [3].

For hydroponic cultivation (from the ancient Greek hýdor, water + pónos, work) is meant a cultivation technique above ground or without soil, where the earth is replaced by an inert substrate, such as expanded clay, coconut fiber, rock wool or zeolite. One of the major issues that may be encountered in protected and/or constrained areas on the Italian territory is the impossibility on the part of agricultural entrepreneurs to get permission to expand their companies. The presence of environmental or landscaping constraints, especially in National and Regional Parks, does not allow new building constructions nor an increased cubic volume [4, 5]. Among the best options granted by the current relevant legislation, is that of creating mobile and removable structures having low environmental impact $[6,7]$.

The term Hydroponics groups together all agricultural soilless cultivation techniques which obviate the problem of soil exhaustion issues and the excessive use of phytosanitary treatments. At present this technique has little diffusion in Italy, involving roughly $3 \%$ of the entire surface of protected cultivations, while in North Europe it accounts for over 50\%. In spite of the advantage this technique offers, soilless cultivations are slow to take-off because of the present high initial costs of investment. Furthermore, the application of hydroponic concept improves water [8], energy [9] sustainability reducing at the same time environmental hazards [10], vulnerabilities [11] and risks [12] and ensuring good standards of ecological sustainability $[13,14]$. Namely, taking into consideration that transport of solid company products on the Italian national territory, takes place mostly through the use of heavy vehicles, mainly powered by diesel fuel, a consumption of 1 liter to cover $5 \mathrm{~km}$ has been estimated. As a 
consequence, an emission of $2,5 \mathrm{~kg} / \mathrm{l}$ of carbon dioxide may be estimated in the atmosphere, which could be avoided if the introduction of hydroponic greenhouse will improve a $0 \mathrm{~km}$ of vegetables market in urban areas improving air quality levels [15] and reducing climate change effects due to greenhouse gases emissions $[16,17]$.

\section{HYDROPONIC GREENHOUSE PROJECT}

The planning and construction of greenhouses is currently regulated by Normative EN 13031-1/2001 defining a Greenhouse as a: "Facility used for the cultivation and/or protection of plants and crops which exploit the transmission of solar radiation under controlled conditions to improve the growth environment, with sufficient dimensions suitable to allow people to work inside them". In particular in Italy UNI 13031-1/2004 "Greenhouses: design and construction" rules this topic according to the European Standard The proposed project consists of a solar greenhouse with an integrated hydroponic cultivation system, to be occasionally adapted in order to become a receptive facility, exploiting an innovative system for cultivation lifting. The result is an architectural structure providing support to an already existing farming activity. The greenhouse will extend over a surface of about $100 \mathrm{~m}^{2}$, with a minimum height of $4 \mathrm{~m}$ and a maximum height of $6 \mathrm{~m}$, according to the frames selected for the cultivation (Figure 1)

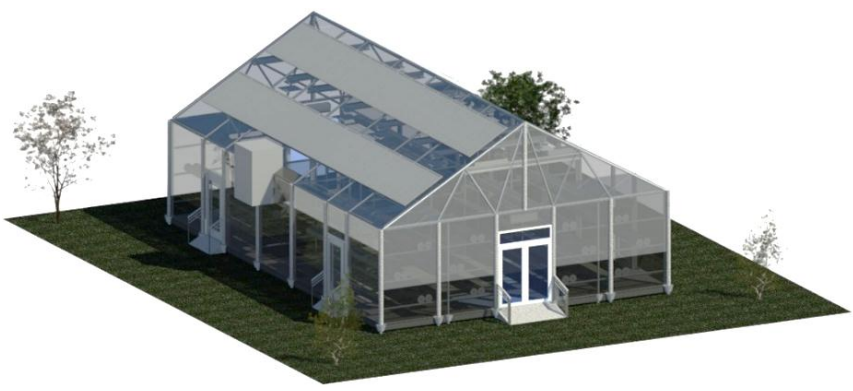

Figure 1. South east view of the hydroponic greenhouse

The greenhouse will be used as a space for the cultivating of vegetable species, but, thanks to its transformability features, new spaces assigned to different destinations of use will be generated. In standard conditions, the greenhouse will be divided into two main modules which will house cultivations, separated by an area in which two spaces will be dedicated to supply facilities (Figure 2); following transformation a central space will be obtained for receptive purposes and the areas which will house the hydroponic system will have a marginal role (Figure 3). The special feature of the project, though, lies in the automated horizontal sliding system of all the cultivation frames, freeing space in the center of the greenhouse. The cultivation of vegetables is carried out above ground, on horizontal tubular supports consisting of suspended mobile bars fitted at the ends of trolleys able to run along rails. Depending on the needs, the supports of the plants can be moved from the central area, to position themselves along the longest walls of the greenhouse, allowing to obtain space to be used for receptive use. The movement of the modules is possible thanks to their sliding on linear rails that are installed on the wall, parallel to each other, along the smaller size of the greenhouse. Once the tubular structure has been moved, a section of the structure that supports the sliding tracks rotates of $90^{\circ}$ and closes the area that hosts the hydroponic system, completely isolating it from the new central space obtained. This insulation guarantees complete climate control, which is differentiated in the two different areas to ensure at the same time the thermohygrometric well-being of both crops and guests. The division of the rooms through transparent PVC walls allows: the guests to enjoy a "green" view, spending their stay surrounded by elements natural but with an appropriate thermal hygrometric condition. The system is perfectly integrated with the supporting structure of the greenhouse. The rectangular structure has an entrance positioned on each shorter side for guests and two entrances positioned on the two major sides, for the exclusive use of the operators to ensure complete isolation and hygienic control of the crops.

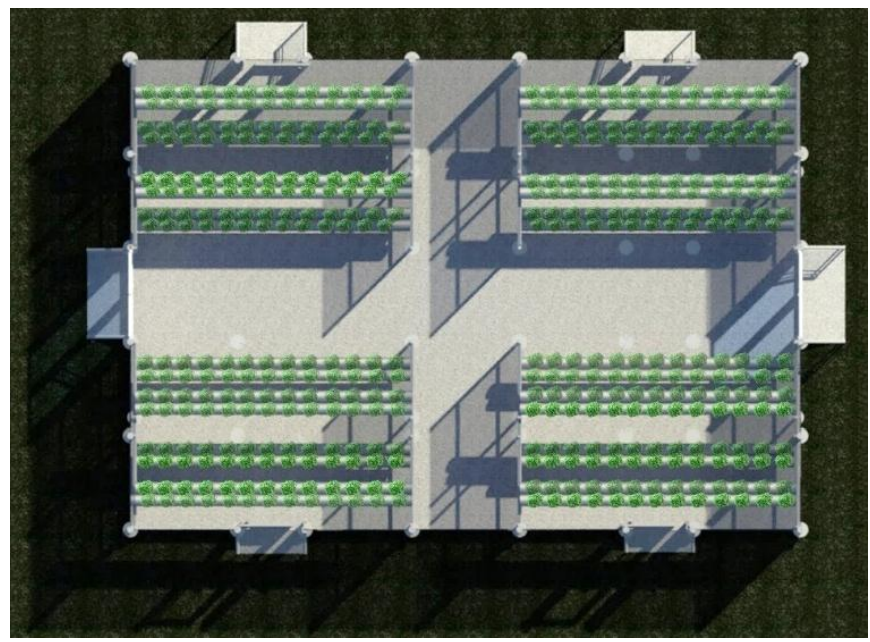

Figure 2. Project of hydroponic greenhouse in standard and transformed conditions with the horizontal movement of the cultivation slots

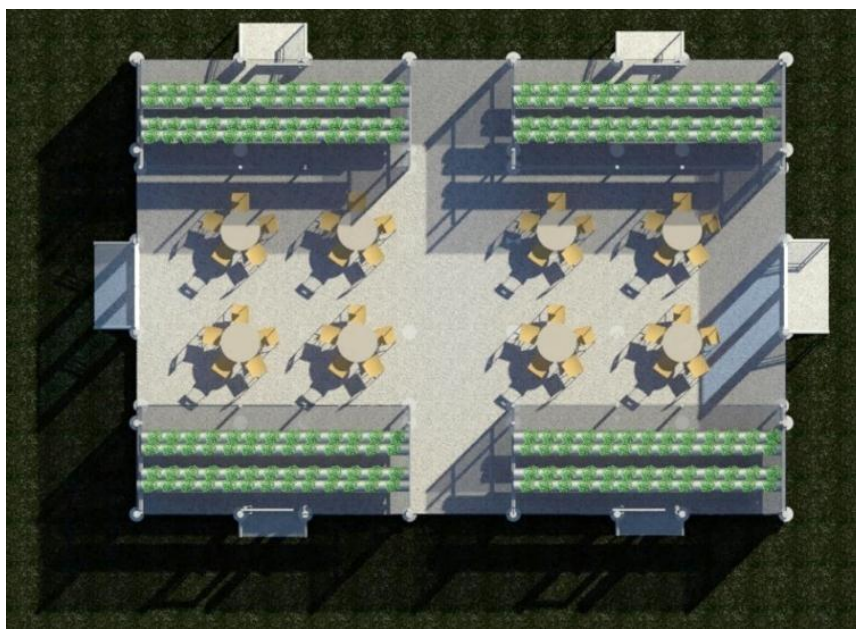

Figure 3. Project of hydroponic greenhouse transformed conditions with the horizontal movement of the cultivation slots

\section{INTEGRATED BIM APPROACH FOR DESIGN AND BUILT MANAGEMENT}

It was decided to develop the project in BIM with the adjunctive aim of testing the evolution of information design processes using this case study. The main focus regards both 
the integration of energy aspects into the design process, in particular the collaboration between the architectural and energy fields, and the management of the building, essential to achieve sustainable architecture and agriculture.

The creation of an integrative digital model of the project was the first result of using software applications such as Autodesk Revit. The 3D model integrates architectural, energetic, mechanical and structural features into the design. The virtual model provides a better understanding of the project to the different disciplines, especially for energy and environmental sustainability aspects.

The transition from 2D modeling to 3D modeling, allowes the creation of intelligent parametric objects that allow you to modify the project in an instantaneous way, defining appearance, dimensions and construction materials and allowing rapid changes in case of need.

The 4D modeling allows designers to visualize the related activities of the construction process. Through the associations between the constructive components and the realization time it is possible to obtain the Gantt and the Timeliner for the control and the management of the construction phases.

The 5D aspects of the model allow to manage and control the costs of the work. From the virtual model it was possible to derive abacus and metric calculations automatically, in fact each 3D component of the project, once inserted the BIM space, is recorded in all its forms and quantities.

The 6D modeling allows to define and manage the energy parameters of the project. Through the insertion of such data it is possible to derive energetic simulations, making sustainable design simpler and faster. These processes analysize the performance of the building from the first design phase, with the result of optimizing overall energy efficiency.

The seventh dimension of BIM is used for the operational management and maintenance of the building and its components throughout the life cycle. (LCA approach) [18].

In the following, is deeply described the BIM approach for the design phase and the building management of energy consumption in the operation period, including even the evaluation of global environmental impact of the "envelope HVAC" system; in fact, the choice of all building materials has been made on the basis of the entire life cycle assessment of the building components and systems.

\section{REGULATORY FRAMEWORK AND BEST AVAILABELE TECNIQUES}

The energy performance of the "envelope-HVAC" building system is the fundamental guiding parameter for the design of all types of greenhouses. The mixed use (hydroponic greenhouse for crops and restauration) need to evaluate carefully the existing regulatory framework for the two different uses, and then to make technical choices suitable for both situations.

As a preliminary consideration, it must be taken into account that in Italy the PAN (National Action Plan), drawn up by the Ministry of Economic Development for agricultural activities, is mainly aimed at achieving the objective of producing energy from renewable sources; as indicated by Directive 2009/28/EC this production should be up to $17 \%$ of total energy consumption in order to limit energy consumption to 131 MTep, by 2020. The forecast of the PAN indicates for agriculture a level of renewable energy in 2020 equal to 22.3 million tons of oil equivalent (MTep). Consequently, ENEA has identified a series of priority actions to be carried out with the aim of providing the necessary technical information to define the possible energy efficiency measures in the agriculture sector (Table 1) [19].

Table 1. Energy efficiency sustainable greenhouse systems

\begin{tabular}{ccccccc}
\hline $\begin{array}{c}\text { Greenhouse } \\
\text { system }\end{array}$ & $\begin{array}{c}\text { Primary energy } \\
\text { consumption } \\
\text { (TEP) }\end{array}$ & tCO 2 & $\begin{array}{c}\text { Primary energy savings with technical } \\
\text { interventions to improve energy } \\
\text { efficiency (20\%) to 2016 (TEP) }\end{array}$ & $\begin{array}{c}\text { Primary energy saving } \\
\text { with installation of PV } \\
\text { systems to 2020 (TEP) }\end{array}$ & $\begin{array}{c}\mathbf{t C O}_{2} \\
\text { saved to } \\
\text { 2016 }\end{array}$ & $\begin{array}{c}\mathbf{t C O}_{2} \\
\text { saved } \\
\text { to 2020 }\end{array}$ \\
\hline Heating & 706.786 & 1.986 .069 & 141.357 & 706.786 & 397.214 \\
Cooling & 16.232 & 45.612 & 3.246 & 1686.0 & 69 \\
Electric users & 8.598 & 24.160 & 1.719 & 8.598 & 9.121 \\
\hline
\end{tabular}

One of the main lines of those efficiency actions concerns the Photovoltaic Greenhouse Systems Sector, where a CNES study reports for Italy a potential of photovoltaic installations calculated on the availability of agricultural infrastructures (sheds and rural canopies), equal to $9.8 \mathrm{GWp}$ to 2015 . According to the Energy \& Strategy Group, the photovoltaic potential on greenhouse surfaces is estimated to be $5.8 \mathrm{GW}$ of installable capacity by 2020 and an additional $27.4 \mathrm{GW}$ considering the potential of uncultivated land and/or poor agricultural performance. Currently, photovoltaic installations in agriculture reach a power of 90-100 MWp, with an average power of $60 \mathrm{~kW}$ on about 2,000 plants. Furthermore, photovoltaic systems could be integrated with the use of storage systems [20] for optimizing the energy autonomy [21].

Regulatory framework - In the case of greenhouses, Italian regulations affirm that the heating must be carried out purely for agricultural purposes to maintain the ideal conditions for crops. Therefore, the HVAC system should not be considered as those for residential uses. However, in this particular case, since the intended use as a restaurant is also considered, the
HVAC plant must comply with the provisions of Presidential Decree 74/2013 governing residential thermal systems, in accordance with the definition of Legislative Decree 192/2005 on the energy efficiency of buildings, with consequent obligation to produce an energy performance certificate.

Regarding the structures and materials for the building envelope currently, in Europe the Standard EN 13031-1:2001 regulates the design and construction of greenhouses and classifies the greenhouses according to the minimum duration expected that the construction project assigns them. This duration depends on one single parameter, the tolerance of the coating material compared with the displacements of the frame. The greenhouses are divided into two main classes, A and B, which differ in their structural characteristics. The belonging to one or the other class is used by the designer to determine the so-called limit states, which can be defined as static situations beyond which the structure no longer meets the performance and safety requirements established in the project. The UNI 10452: 1995 standard classifies the corrugated and alveolar sheets, based on transparent, colourless or translucent 
plastic materials for use in greenhouses. It defines the profile, the shape, the dimensions and the qualitative characteristics of the different types of sheets, indicating the relative test methods. In particular the standard is applied to the alveolar or corrugated polymethylmethacrylate (PMMA) sheets; bioriented vinyl polychloride (PVC); honeycomb type (UV protected) polycarbonate (PC); glass fibre reinforced polyester (GRP), corrugated and UV protected. The choice between sheets is based on total transmittance of the incident radiation, greenhouse effect, mechanical resistance and durability in operation (for which they must be guaranteed over 10 years).

\section{DESIGN METHODOLOGY}

In order to select best materials, a life cycle analysis has been carried out in the BIM environment, using the appropriate TALLY® application. In particular, for selected materials it was assessed, referring to ISO 14042 and 14043, the total environmental damage produced during the phases of production, installation, use and disposal. The following figure show the results obtained by analysing the production of $1 \mathrm{~kg}$ of steel (see Table 2 for detailed calculation) and $1 \mathrm{~kg}$ of aluminium, assessing the overall damage and reporting in detail also the consumption of resources and the production of substances that contribute to this damage (Figure 4); the proposed methodology allows the designer to evaluate even specific critical issues related to specific installation areas $[22$, 23].

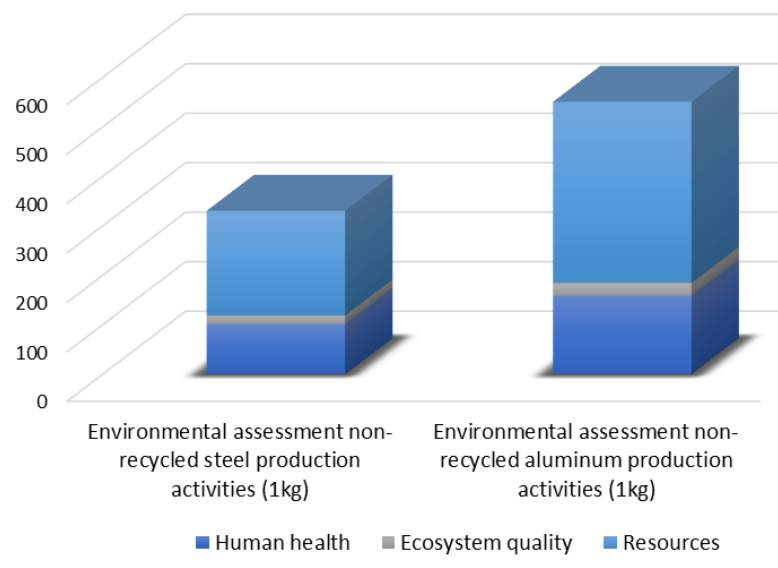

Figure 4. Environmental assessment of non-recycled steel production activities $(1 \mathrm{~kg})$ and of non-recycled aluminium production activities $(1 \mathrm{~kg})$ (Measure unit: $\mathrm{mPt}$ )

Table 2. Environmental assessment of non-recycled steel production activities $(1 \mathrm{~kg})$

\begin{tabular}{|c|c|c|c|c|c|c|c|}
\hline & \multirow[b]{2}{*}{ Impact category } & \multicolumn{3}{|c|}{ CHARACTERIZATION } & \multicolumn{3}{|c|}{ WEIGHTED EVALUATION } \\
\hline Damage category & & Measure unit & \multirow{2}{*}{$\begin{array}{c}\text { Quantity } \\
7,6 \mathrm{E}-7\end{array}$} & Measure unit & Measure unit & Qu & ity \\
\hline \multirow{6}{*}{ Human health } & Carcinogens & DALY & & \multirow{6}{*}{$3,9 \mathrm{E}-6$} & $\mathrm{mPt}$ & 19,6 & \multirow{6}{*}{101} \\
\hline & Respiratory organics pollutants & DALY & $6,4 \mathrm{E}-9$ & & $\mathrm{mPt}$ & 0,16 & \\
\hline & Respiratory inorganics pollutants & DALY & $2,1 \mathrm{E}-6$ & & $\mathrm{mPt}$ & 53,2 & \\
\hline & Climate changes & DALY & $1,1 \mathrm{E}-6$ & & $\mathrm{mPt}$ & 28 & \\
\hline & Radiations & DALY & $1,1 \mathrm{E}-9$ & & $\mathrm{mPt}$ & 0,003 & \\
\hline & Ozone layer depletion & DALY & $1,2 \mathrm{E}-9$ & & $\mathrm{mPt}$ & 0,003 & \\
\hline \multirow{3}{*}{$\begin{array}{c}\text { Ecosystem } \\
\text { quality }\end{array}$} & Ecotoxicity & $\mathrm{PDF}^{*} \mathrm{~m}^{2} \mathrm{yr}$ & 0,05 & \multirow{3}{*}{0,22} & $\mathrm{mPt}$ & 4,1 & \multirow{3}{*}{17,5} \\
\hline & Acidification /Eutrophication & $\mathrm{PDF}^{*} \mathrm{~m}^{2} \mathrm{yr}$ & 0,08 & & $\mathrm{mPt}$ & 6,21 & \\
\hline & Land use & $\mathrm{PDF}^{*} \mathrm{~m}^{2} \mathrm{yr}$ & 0,09 & & $\mathrm{mPt}$ & 7,17 & \\
\hline \multirow{2}{*}{ Resources } & Minerals & MJ surplus & 1,39 & \multirow{2}{*}{6,32} & $\mathrm{mPt}$ & 46,7 & \multirow{2}{*}{211,7} \\
\hline & Fossil fuels & MJ surplus & 4,93 & & $\mathrm{mPt}$ & 165 & \\
\hline \multicolumn{2}{|r|}{ Total } & & & & $\mathbf{m P t}$ & \multicolumn{2}{|c|}{330,2} \\
\hline
\end{tabular}

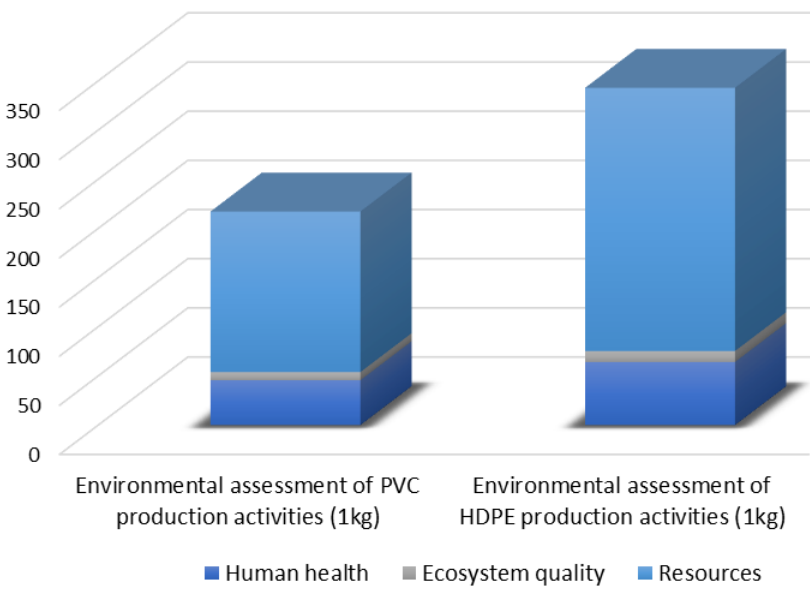

Figure 5. Environmental assessment of PVC production activities $(1 \mathrm{~kg})$ and of HDPE production activities $(1 \mathrm{~kg})$

(Measure unit: $\mathrm{mPt}$ )

According to the LCA results the supporting structure [24], was made of modular galvanized steel, allows to better personalize shape and dimensions, according to client needs.
Despite being very thin, the protective layer is impenetrable for aggressive species, and will be able to reduce zinc corrosion to a value equal to $1 / 17-1 / 18$ of the speed at which unprotected steel dissolves.

As far as coating materials are concerned, the choice made was of a type of bi-oriented rigid PVC preferred to HDPE taking into account the LCA results shown in Figure 5. This material will allow the passage of short infra-red rays (heat rays) and will prevent the leaking of far infrared rays emitted by the soil (black- bodies) thus ensuring the greenhouse effect; it will furthermore be able to transmit the rays which will ensure photosynthesis in plants, however partially preventing the passage of ultraviolet rays, inhibitors of the photosynthetic process. Thanks to the special bi-orientation treatment, panels will be shockproof and hail resistant. Indeed, their resilience in traction is superior to $1200 \mathrm{KJ}$ sqm, i.e. between two and three times more than normal PVC panels; these values will remain stable also at low temperatures (up to $-60^{\circ} \mathrm{C}$ ).

The integrated approach typical of the BIM methodology makes it possible immediately to check the validity of the choices coming from the LCA approach also from the point of view of energy performance and then, of course, triggering an iterative optimization process. 
The design choices were in fact directed to an "envelopeHVAC" system with high energy performance (near zero energy building) with strong production of energy from renewable sources.

The energy analysis of the building was carried out with a calculation that took into account different energy flows, interacting with each other; the heat is added to the greenhouse by the incident solar radiation (sr) and by the heating system (cHa), whereas lost due to the ventilation through outdoor air or air leakage (ea) and heat transfer through the greenhouse roof (r). Also, internal thermal loads such as plants (p) and soil (f) and the HVAC system (h) are taken into account (Table 3).

At the same time, simulations were carried out monitoring the micro-climatic parameters, modified by the greenhouse coverings, that most influence the physiology of plants: temperature, thermal radiation, air humidity, air flows and $\mathrm{CO}_{2}$ concentration.

Table 3. Parameters of the main greenhouse energy flows

\begin{tabular}{|c|c|c|c|c|c|c|c|c|}
\hline Parameters & Indoor air (a) & Plant (p) & Soil (f) & Roof (r) & Conditioning (h) & Sun (sr) & Outdoor air (ea) & Sky (s) \\
\hline Air & $*$ & $\mathrm{c}, \mathrm{I}$ & $\mathrm{c}, \mathrm{I}$ & $\mathrm{c}, \mathrm{I}$ & $\mathrm{c}$ & - & i & - \\
\hline Plant & $\mathrm{c}, \mathrm{I}$ & $*$ & $\mathrm{r}$ & $\mathrm{r}$ & $\mathrm{r}$ & $\mathrm{sr}$ & - & r' \\
\hline Ground & $\mathrm{c}, \mathrm{I}$ & $\mathrm{r}$ & $\mathrm{k}$ & $\mathrm{r}$ & $\mathrm{r}$ & $\mathrm{sr}$ & - & r' \\
\hline Roof & $\mathrm{c}, \mathrm{I}$ & $\mathrm{r}$ & $\mathrm{r}$ & $*$ & $\mathrm{r}$ & $\mathrm{sr}$ & $\mathrm{c}$ & $\mathrm{r}^{\prime}$ \\
\hline \multicolumn{9}{|c|}{$\mathrm{c}=$ convection; $\mathrm{k}=$ conduction; $\mathrm{sr}=$ solar radiation; $\mathrm{r}^{\prime}=$ transmissivity of the roof if greater than 0} \\
\hline \multicolumn{9}{|c|}{$\mathrm{I}=$ latent heat; $\mathrm{r}=$ radiation; $\mathrm{i}=$ infiltration and/or heat loss } \\
\hline \multicolumn{9}{|c|}{$\begin{array}{c}\text { Air: } \mathrm{cHp}+\mathrm{cHf}+\mathrm{cHr}+(\mathrm{cHr})+\mathrm{iH}=0 \\
\text { Vegetal canopy: } \mathrm{cHa}+\mathrm{IHa}+\mathrm{rHf}+\mathrm{rHr}+(\mathrm{rHh})+\mathrm{srH}+\mathrm{rHs}=0 \\
\text { Soil: } \mathrm{cHa}+\mathrm{Iha}+\mathrm{rHp}+\mathrm{khf}+\mathrm{rHr}+(\mathrm{rHh})+\mathrm{srH}+\mathrm{rHs}=0 \\
\text { Roof: } \mathrm{cHa}+\mathrm{IHa}+\mathrm{rHp}+\mathrm{rHf}+(\mathrm{rHh})+\mathrm{srH}+\mathrm{cHea}+\mathrm{rHs}=0 \\
\text { Conditioning (heating/cooling): } \mathrm{cHa}+\mathrm{rHp}+\mathrm{rHf}+\mathrm{rHr}+\mathrm{hH}=0\end{array}$} \\
\hline
\end{tabular}

Source: ENEA. Energy conservation and renewable energies for green house heating. FAO, CNRE n.2, Guidelines.

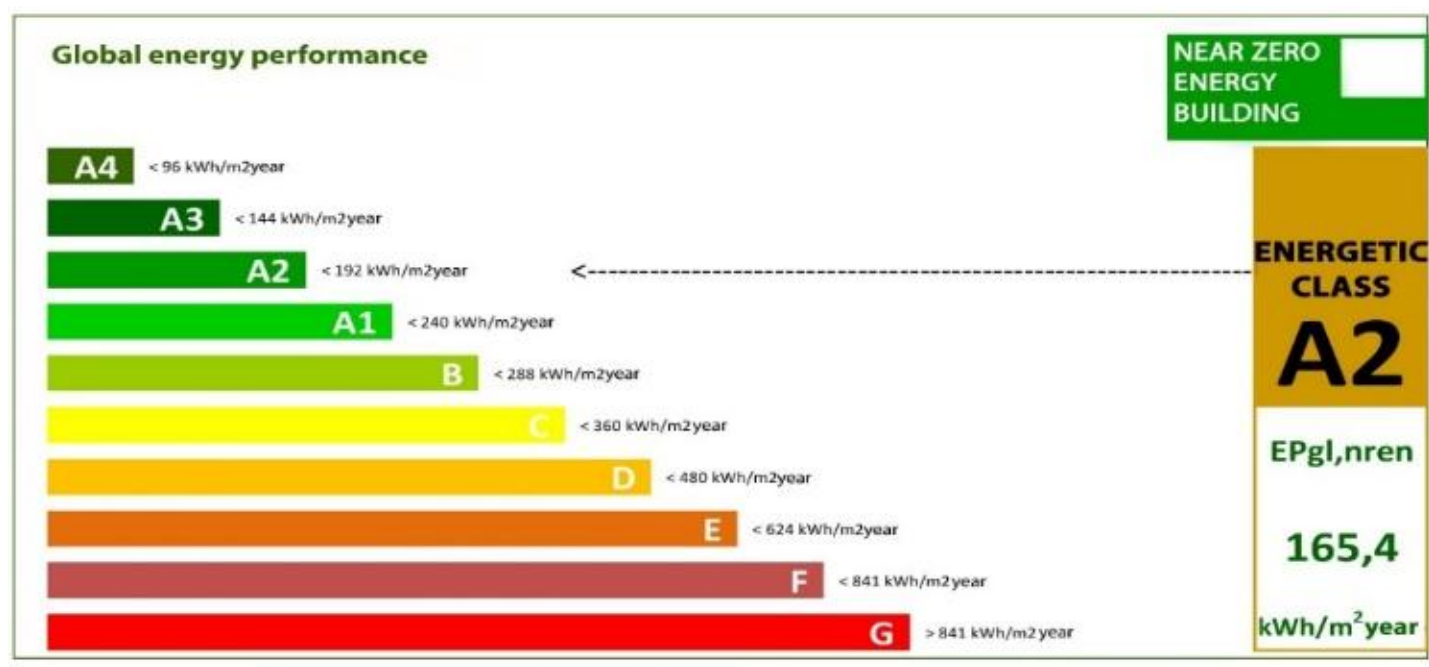

Figure 6. Energy performance certificate

The temperature in fact directly influences the speed of all the biochemical reactions of plants (such as respiration, photosynthesis, other anabolic and catabolic reactions, etc.), driving some macroscopic phenomena (growth, transpiration, etc.). The optimal management of plant productions in a protected environment is strongly conditioned by both the internal climatic factors (air temperature, ventilation, relative humidity, solar radiation and lighting, plant health) and by the interactions between the various factors in relation to the microclimatic conditions (above all from the interactions between solar radiation, light, temperature, humidity) in the various stages of physiological and productive growth and development. The energy analysis was carried out through a digital twin of a greenhouse made in BIM environment using MC4 tool for Revit and, according to the Italian legislation, the energy performance certificate (APE) was also produced using ArchiEnergy software pointed out by Sapienza University; the overall energy performance coming from the simulations is equal to $165.4 \mathrm{kwh} / \mathrm{m}^{2}$ year, that classifies the building as "near zero energy building" as shown in the Figure 6.
The HVAC system is based on an air heat pump (10 KW) able to control the interior climate by regulating temperatures and humidity. Fan-Coils produce a forced-air flow providing an active air recirculation involving the entire environment and maintaining a pleasant and uniform internal climate. This plant could be improved with a unity of production of hot water, working with heat recovered from the external heat pump unity.

Furthermore, another enthalpy heat recovery device will supply up to $1000 \mathrm{~m} 3 / \mathrm{h}$ of exchange air, meeting air hygiene standards and complying with the latest regulations. The system will be made up of a structure in special treated paper which will allow for the crossing of flows exchanging heat energy between one another.

The greenhouse will extend over a surface of about $100 \mathrm{sqm}$, and according with Italian Action Plan cited below it host a monocrystalline PV system of $12 \mathrm{kWp}$ tilted by $30^{\circ}$, guaranteeing maximum productiveness able to produce $13.000 \mathrm{kWh}$ each year that is more than $70 \%$ of the total amount of energy consumption of the greenhouse $(20.220$ 
$\mathrm{kwh} /$ year).

Another LCA software - software SimaPro - was used for a posteriori comparative evaluation between the chosen HVAC plant and a traditional conditioning system normally used for catering business (Table 4).

Table 4. LCA of two HVAC systems

\begin{tabular}{|c|c|c|c|}
\hline \multirow{2}{*}{$\mathrm{mPt}$} & \multirow{2}{*}{$\begin{array}{c}\text { Heat pump } \\
(1 \mathrm{~kW})\end{array}$} & $\begin{array}{c}\text { HVAC Plant with air handling unit } \\
(1 \mathrm{~kW})\end{array}$ \\
\cline { 3 - 4 } & \multirow{3}{*}{$17.896,1$} & Condensing boiler & $3.069,1$ \\
\cline { 3 - 4 } & & Cooling unit & $11.926,5$ \\
\cline { 3 - 4 } & & Hear handling unit $\left(1 \mathrm{~m}^{3} / \mathrm{h}\right)$ & 204,4 \\
\cline { 3 - 4 } & & Circulation pumps & $14.552,6$ \\
\hline $\mathrm{mPt}$ total & $17.896,1$ & \multicolumn{2}{|c|}{$29.752,6$} \\
\hline
\end{tabular}

To complete the assessment of the overall damage to the health and ecosystem of the greenhouse, it was also considered the one related to the production unit of $1 \mathrm{kWh}$ of photovoltaic system in polycrystalline silicon. The total damage is $467 \mathrm{mPt}$ compared to a damage avoided during the 25 years of use of $2.620 \mathrm{mPt}$

\section{CONCLUSIONS}

The main advantages of hydroponic agriculture are higher yields and water efficiency and the continuous production throughout the year [25]. The most frequent vegetables and fruit inside hydroponics greenhouse are cucumbers, tomatoes, eggplants, peppers, lettuce, pot herbs and strawberries.

A study on the comparison of water, land, and energy requirements for lettuce cultivation using conventional agricultural methods and hydroponic system, showed the advantages and disadvantages.

As an example, in terms of yield per area, the hydroponic production of lettuce was found to be 10 times greater than that of its conventional equivalent [26]. Hydroponic lettuce production had an estimated 100 times lower water demand than the conventional method.

The energy demands associated with water pumps, supplemental artificial lighting, and mostly heating and cooling loads in a hydroponic greenhouse, is 100 times greater than the conventional agricultural method.

The construction of a chain of sustainable energy greenhouses in Italy and more generally in the Mediterranean region is certainly possible, environmentally desirable and economically not excessively burdensome.

In particular, in technical terms, the problems are mainly related to the use of the solar resource for electricity demand and essentially due to the discontinuity of solar energy during the year; consequently, there is the need to use crops and suitable systems and production processes to maximize the use in real time or with short storage periods of photovoltaic electricity produced during the year.

The hydroponic cultivations are well suited to this purpose and the use the structure also for restaurant purposes would allow to amortize much more quickly the economic costs related to the implementation of a photovoltaic system with dimensions exceeding $5 \mathrm{kWp}$.

To increase the overall sustainability of the system and therefore think of being able to use it extensively even in protected and / or valuable natural areas, it is however necessary to carefully evaluate the environmental impacts associated with the entire life cycle of the structure of the greenhouse itself and its HVAC and energy installations.

The design methodology described in the paper with the use of dedicated software operating synergistically in a BIM environment make possible to optimize all the design parameters in an iterative manner and achieve optimal results in terms of minimizing impacts on environment and human health.

The proposed solution is extremely performing from the energy point of view during the using phase, being the hydroponic greenhouse in the category of near zero energy but is also an environmentally sustainable construction as all the design solutions chosen have reduced environmental impacts with particular regard to the areas of resource consumption and of pollution of soil and groundwater.

\section{REFERENCES}

[1] REPLACE WITH: FAO. (2017). Food and Agriculture Driving Action Across the 2030 Agenda for Sustainable Development. http://www.fao.org/3/a-i7454e.pdf

[2] G7 Agriculture Ministers Meeting Communiqué. Empowering farmers, developing rural areas and enhancing cooperation to feed the planet. http://www.g7italy.it/sites/default/files/documents/Com unicato.pdf, accessed on Oct. 14-15, 2017.

[3] Starting paper from the EIP-AGRI Focus Group on Circular https://ec.europa.eu/eip/agriculture/sites/agrieip/files/eipagri_fg_circular_horticulture_starting_paper_2017_en.p df.

[4] De Santoli, L., Astiaso Garcia, D., Violante, A.C. (2008). Planning of flood defense management and rehabilitation of the natural habitat in the downstream part of the river Tiber. Geo-Environment and Landscape Evolution III. WIT Transaction on the Built Environment, 100: 25-34. https://doi.org/10.2495/GEO080031

[5] Di Matteo, U., Pezzimenti, P.M., Astiaso Garcia, D. (2016). Methodological proposal for optimal location of emergency operation centers through multi-criteria approach. $\quad$ Sustainability, $\quad 8(1)$ : $\quad 1-12$. https://doi.org/10.3390/su8010050

[6] Guidi, G., Gugliermetti, F., Astiaso Garcia, D. \& Violante, A.C. (2009). Influence of environmental, economic and social factors on a site selection index methodology for a technological centre for radioactive waste management. Chemical Engineering Transactions, 18: 505-510. https://doi.org/10.3303/CET0918082

[7] Astiaso Garcia, D. (2016). Can radiant floor heating systems be used in removable glazed enclosed patios meeting thermal comfort standards? Building and Environment, 106: 378-388. https://doi.org/10.1016/j.buildenv.2016.07.013

[8] Castellar, J.A.C., Formosa, J., Fernández, A.I., Jové, P., Bosch, M.G., Morató, J., Brix, H., Arias, C.A. (2019). Cork as a sustainable carbon source for nature-based solutions treating hydroponic wastewaters - Preliminary batch studies. Science of the Total Environment, 650: 267-276. https://doi.org/10.1016/j.scitotenv.2018.08.365

[9] Tavakoli, S., Alghassi, A., Perinpanayagam, S. \& Garcia, D.A. (2017). Skill development in the wind energy sector: A serious game development approach. IEEE Global 
Engineering Education Conference, EDUCON, pp. 2-9. https://doi.org/10.1109/EDUCON.2017.7942814

[10] Al Shami, A., Harik, G., Alameddine, I., Bruschi, D., Garcia, D.A., El-Fadel, M. (2017). Risk assessment of oil spills along the Mediterranean coast: A sensitivity analysis of the choice of hazard quantification. Science of the Total Environment, 574: 234-245. https://doi.org/10.1016/j.scitotenv.2016.09.064

[11] Harik, G., Alameddine, I., Maroun, R., Rachid, G., Bruschi, D., Astiaso Garcia, D., El-Fadel, M. (2017). Implications of adopting a biodiversity-based vulnerability index versus a shoreline environmental sensitivity index on management and policy planning along coastal areas. Journal of environmental management, $\quad 187$ : 187-200. https://doi.org/10.1016/j.jenvman.2016.11.038

[12] Astiaso Garcia, D., Bruschi, D. (2016). A risk assessment tool for improving safety standards and emergency management in Italian onshore wind farms, Sustainable Energy Technologies and Assessments, 18: 48-58. http://dx.doi.org/10.1016/j.seta.2016.09.009

[13] Astiaso Garcia, D. (2017). Green areas management and bioengineering techniques for improving urban ecological sustainability. Sustainable Cities and Society, 30: 108-117. http://localhost/conversion/tmp/scratch/dx.doi.org/10.10 16/j.scs.2017.01.008

[14] Astiaso Garcia, D., Canavero, G., Ardenghi, F., Zambon, M. (2015). Analysis of wind farm effects on the surrounding environment: Assessing population trends of breeding passerines. Renewable Energy, 80: 190-196. http://dx.doi.org/10.1016/j.renene.2015.02.004

[15] Gugliermetti, L., Astiaso Garcia, D. (2018). A cheap and third-age-friendly home device for monitoring indoor air quality. International Journal of Environmental Science and Technology, 15(1): 185-198. http://doi.org/10.1007/s13762-017-1382-3

[16] Carbonara, E., Tiberi, M., Astiaso Garcia, D. (2015). Analysis of energy performance improvements in Italian residential buildings. Energy Procedia, 82: 855-862. https://doi.org/10.1016/j.egypro.2015.11.826

[17] Astiaso Garcia, D., Sangiorgio, S., Rosa, F. (2015). Estimating the potential biomasses energy source of forest and agricultural residues in the Cinque Terre
Italian National Park. Energy Procedia, 82: 674-680. https://doi.org/10.1016/j.egypro.2015.11.791

[18] Cumo, F., Guidi, G., Francione, V., Ortore, E. (2006). A methodological proposal for monitoring atmospheric pollutants by means of satellites. CHISA 2006. Proceedings of the 17th International Congress of Chemical and Process Engineering.

[19] Cumo, F., Sferra, A., Piras, G., Mancini, F., Barbanera, F., Tiberi, M., Sforzini, V., De Lieto Vollaro, B., Pennacchia, E., Spiridigliozzi, G. (2016). La metodologia bim come strumento per una efficiente progettazione e gestione degli impianti degli edifici. Report Ricerca di Sistema Elettrico. http://cesta.casaccia.enea.it/bimdb/upload/61_RdS_PA R2015-149.pdf

[20] Astiaso Garcia, D. (2017). Analysis of non-economic barriers for the deployment of hydrogen technologies and infrastructures in European countries. International Journal of Hydrogen Energy, 42(10): 6435-6447. https://doi.org/10.1016/j.ijhydene.2017.01.201

[21] Groppi, D., Astiaso Garcia, D., Lo Basso, G., De Santoli, L. (2019). Synergy between smart energy systems simulation tools for greening small Mediterranean islands. Renewable Energy, 135: 515-524. https://doi.org/10.1016/j.renene.2018.12.043

[22] Campiotti, C. A., Viola, C., Scoccianti, M. (2011). L'efficienza energetica nel settore agricoltura, Quaderni energia, Roma, ENEA.

[23] De Santoli, L. (2006). Analisi del ciclo di vita del sistema edificio-impianto, Palombi Editori, Roma, Italy.

[24] Sferra, A.S. (2013). Obiettivo “quasi zero". Un percorso verso la sostenibilità ambientale. Francoangeli, Milano, Italy.

[25] Brechner, M., Both, A.J. (2014). Hydroponic Lettuce Handbook, Cornell Controlled Environment Agriculture. Cornell University.

[26] Barbosa G.L., Gadelha F.D.A., Kublik N., Proctor, A., Reichelm, L., Weissinger, E., Wohlleb, G.M., Halden, R.U. (2015). Comparison of land, water, and energy requirements of lettuce grown using hydroponic vs. conventional agricultural methods. International Journal of Environmental Research and Public Health, 12(6): 6879-6891. https://doi.org/10.3390/ijerph120606879 